\title{
Desafios na adaptação dos graduandos em enfermagem no Ensino Remoto Emergencial (ERE): um relato de experiência
}

\author{
Robervam de Moura Pedroza ${ }^{1}$ \\ Kátia de Oliveira Leite ${ }^{2}$ \\ Maria Eduarda Cavalcanti Vieira ${ }^{3}$ \\ Nathália Camilly da Silva Neves ${ }^{4}$ \\ Thallyta Juliana Pereira da Silva
}

\section{RESUMO}

Com o propósito de mitigar os impactos na Educação causados pela pandemia do coronavírus, as instituições de ensino passaram a utilizar as atividades remotas. O presente estudo objetivou relatar a experiência de aprendizagem dos alunos do curso de Bacharelado em Enfermagem do Instituto Federal de Educação, Ciência e Tecnologia de Pernambuco (IFPE) - Campus Pesqueira durante o Ensino Remoto Emergencial (ERE). Trata-se de um relato de experiência no qual os discentes descreveram suas trajetórias nessa modalidade de ensino. A estratégia se fez necessária face ao novo contexto e constitui-se em um desafio, visto que a totalidade dos estudantes estavam habituados ao ensino presencial. Constatou-se que os alunos conseguiram se adaptar e adquirir habilidades para desenvolver a autoaprendizagem, considerada essencial no processo de construção do conhecimento.

Palavras-chaves: Metodologias ativas. Tecnologias no ensino-aprendizagem. Ensino Remoto Emergencial. COVID-19.

\footnotetext{
1 robervam@pesqueira.ifpe.edu.br - IFPE - Campus Pesqueira

${ }^{2}$ kol@discente.ifpe.edu.br - IFPE - Campus Pesqueira

${ }^{3}$ mecv@discente.ifpe.edu.br - IFPE - Campus Pesqueira

${ }^{4}$ nahneves86@gmail.com - IFPE - Campus Pesqueira

${ }^{5}$ tjps@discente.ifpe.edu.br - IFPE - Campus Pesqueira
} 
Challenges for adapting undergraduate nursing students in Emergency Remote Education: An Experience Report

\section{ABSTRACT}

In order to mitigate the impacts caused by the Coronavirus pandemic, educational institutions started to use remote activities. This study aims to report the learning experience of students of the bachelor's degree in nursing at IFPE Campus Pesqueira during Emergency Remote Education (ERE). It is an experience report, through which the students describe their trajectory in this type of teaching. The strategy was necessary in view of the new context and was a challenge, since all students were accustomed to face-to-face teaching. It was found that the students obtained their adaptation and acquired skills to develop self-learning, considered essential for the process of knowledge construction.

Keywords: Active methodologies. Technologies in teaching-learning. Emergency Remote Teaching. COVID-19. 
No dia 18 de março de 2020, em consequência do aumento no número de casos do novo coronavírus, o Ministério da Educação (MEC) interrompeu as aulas presenciais em todo território nacional por meio da Portaria $\mathrm{n}^{\circ}$ 343, de 17 de março de 2020 (BRASIL, 2020). Diante desse cenário, as instituições de ensino buscaram estratégias para desenvolver suas atividades com o uso de tecnologias digitais de informação e comunicação a fim de manter o isolamento social e diminuir os impactos causados pelo COVID-19 (ARRUDA, 2020).

No que concerne à suspensão das aulas presenciais, a tomada de decisão de muitos estabelecimentos de ensino, federais e estaduais, deliberaram o Ensino Remoto Emergencial (ERE) como uma forma viável de aprendizagem, uma estratégia plausível para a educação durante essa situação. Essa modalidade integrou o cotidiano de boa parte das instituições que buscaram manter o vínculo entre discentes e docentes no espaço virtual para a formação acadêmica (DUTRA E SILVA et al., 2020).

Diante disso, as ferramentas on-line receberam destaque nos espaços educacionais. $O$ uso de mecanismos, como Google Meet, Google Classroom, Google Documents, Jamboard, Google Forms, Socrative etc, somados às metodologias ativas, visaram auxiliar a vida acadêmica. Esses métodos representaram uma alternativa capaz de estimular o protagonismo do aluno, tornando-o responsável por gerir o próprio tempo. Isso possibilitou a transformação do estudante no processo de ensino-aprendizagem de forma remota (MOREIRA; HENRIQUES; BARROS, 2020; MACHADO, 2018).

As práticas educativas do ERE são bastante confundidas com o Ensino a Distância (EaD) e, visto que há diferença entre essas duas modalidades, faz-se necessário distingui-las. O EaD é uma categoria - com legislação específica no Brasil -, de cursos lecionados a distância, com boa estruturação pedagógica, incluindo a apresentação dos objetivos e do público-alvo (GOEDERT; ARNDT, 2020). O ERE é um modelo de ensino mais recente, utilizado em consequência da situação epidemiológica no país, pois as aulas presenciais trariam riscos à saúde da sociedade (WANDSCHEER, 2020).

No que se refere ao curso de enfermagem da IFPE, os objetivos de aprendizagem e as estratégias pedagógicas do ensino remoto não diferem das do ensino presencial, pois, independente da modalidade, o propósito é executar o Projeto Pedagógico de Curso (PPC) vigente. $O$ contexto atual, entretanto, exigiu a substituição das aulas presenciais pela utilização em casa - de tecnologias digitais, algumas já existentes no modelo tradicional, mas que passaram a representar estratégias indispensáveis nessa nova realidade de ensino. Além disso, o termo remoto refere-se somente à troca do ambiente presencial para o virtual. Dessa forma, as aulas acontecem de modo síncrono - webconferências, aulas expositivas em tempo real -, e as atividades continuam de forma assíncrona no espaço do Ambiente Virtual de Aprendizagem (AVA) durante a semana. (JOYE, MOREIRA; ROCHA, 2020; HODGES et al., 2020).

A atuação do educador no EaD conta com mecanismos de preparação para disponibilizar os conteúdos pedagógicos por meio de diversos programas on-line. Todavia, no ERE, o docente surge como protagonista de todo o material, desde a realização de videoaulas à seleção e 
formação de conteúdo, além da responsabilidade de deliberações metodológicas aos impasses relacionados à acessibilidade equitativa e tecnológica. Nesse panorama, o estudante do EaD possui características de uma pessoa madura com motivações externas que o insere nesse ambiente on-line de caráter autônomo; o do ERE dispõe de uma motivação emergencial (JOYE; MOREIRA; ROCHA, 2020).

Assim sendo, durante esse período surgiram algumas dificuldades no processo de adaptação dos acadêmicos, como a falta de acesso à internet, a falta de capacitação dos professores para o uso das tecnologias, a sobreposição de atividades, a adaptação às novas plataformas virtuais; que de alguma forma também repercutiram na saúde mental desses alunos. Apesar dessas fragilidades encontradas, as entidades de ensino procuraram formas de minimizar os impactos causados pelo ensino remoto diminuindo os momentos síncronos, disponibilizando os materiais de apoio, dispondo os dados para o uso da internet, bem como os materiais impressos (APPENZELLER et al., 2020; GOMES et al., 2020).

Com isso, é importante ressaltar que o presente estudo refere-se a um relato de experiência, no qual abordará algumas circunstâncias e sentimentos dos discentes durante o ERE. Ademais, mostra-se fundamental a reflexão acerca desses momentos vivenciados pelos estudantes, dado que as mudanças em consequência do cenário pandêmico impactaram a trajetória acadêmica de muitos deles.

Desse modo, objetiva-se, aqui, relatar a experiência de aprendizagem dos alunos do curso de Bacharelado em Enfermagem do Instituto Federal de Educação, Ciência e Tecnologia de Pernambuco (IFPE) - Campus Pesqueira durante o ERE.

\subsection{Tipo de estudo}

Trata-se de um estudo descritivo do tipo relato de experiência baseado na vivência de um grupo de quatro estudantes do segundo módulo - que corresponde a um semestre, ou período, de um total de dez - do curso de Bacharelado em Enfermagem de uma instituição pública no interior de Pernambuco. A construção do referido relato se fez a partir da narrativa dos próprios alunos sobre as experiências vivenciadas por eles nos componentes curriculares: Programa Tutorial II e Iniciação à Pesquisa em Saúde.

\subsection{Componentes curriculares}

A elaboração deste relato aconteceu de forma remota por meio da divisão das atribuições entre os discentes, as quais foram definidas em reuniões virtuais sob a orientação do professorfacilitador do curso supracitado. Essas reuniões ocorreram durante a semana com a participação do orientador-tutor e dos orientandos, além do auxílio das professoras da disciplina de Iniciação à Pesquisa em Saúde.

Ao cursarem Programa Tutorial II e Iniciação à Pesquisa em Saúde, os estudantes do segundo módulo de enfermagem despertaram seus potenciais de adaptação à realidade do ensino remoto. Essas disciplinas visavam instigar a qualificação profissional dos estudantes por intermédio de pesquisas no âmbito da saúde, mediante a orientação metodológica e trabalho em 
equipe, o que também contribuiu para o desenvolvimento dos vínculos entre os alunos e professores.

Com o intuito de minimizar a sobrecarga de trabalho para os discentes, a instituição propôs a oferta dos componentes curriculares de forma gradual em três momentos, que ficaram classificados por módulos, cada um composto por duas ou três disciplinas com duração de três semanas cada. $O$ relato foi construído baseado na vivência dos estudantes durante esse processo adaptativo do ERE no decorrer do primeiro momento das aulas, que ocorreram de forma modular no período de agosto a outubro de 2020.

O componente Iniciação à Pesquisa em Saúde traz na sua ementa a proposta de estudar o processo de investigação científica aplicado à saúde - enfermagem. A epistemologia, os métodos e as aplicações têm como pressuposto fundamental o desenvolvimento do pensamento científico. Já o Programa Tutorial II propõe desenvolver o processo grupal envolvendo docentes e discentes na discussão das dificuldades de vinculação e adaptação dos estudantes à universidade e na construção de uma identidade profissional individual e coletiva.

\subsection{Sujeitos do Estudo}

Por se tratar de um relato de experiência, os sujeitos do presente relato são representados pelos próprios alunos do curso de Bacharelado em Enfermagem. Como já exposto, o grupo é representado por quatro discentes do segundo módulo.

\subsection{Instrumento de coleta, operacionalização e análise dos dados}

Utilizou-se como instrumento de coleta de dados o memorial reflexivo em relação à trajetória do discente, proposto pela disciplina Programa Tutorial II - ver apêndice -, elaborado ao longo do primeiro módulo de aulas. Essa ferramenta teve como objetivo incentivar os alunos a explorar suas vivências, sentimentos e expectativas durante as semanas no ERE. $O$ docente da disciplina, portanto, em comum acordo com os discentes, disponibilizou o referido memorial reflexivo a cada um dos sujeitos para a construção do relato.

A fim de operacionalizar o estudo, foram utilizadas ferramentas digitais - WhatsApp e email -, com o intuito de proporcionar a interação entre discentes e docentes, e que funcionaram como principal meio de comunicação. Para os encontros síncronos foi utilizado o Google Meet; para as atividades assíncronas, o Google Classroom.

A análise dos dados se deu a partir da leitura e fichamento dos memoriais reflexivos, estes foram descritos de maneira anônima, sem a divulgação direta dos depoimentos. Dessa maneira, foram respeitados todos os critérios éticos previamente estabelecidos na Resolução N ${ }^{\circ} 510$ de 07 de abril de 2016, do Conselho Nacional de Saúde - CNS (BRASIL, 2016).

\subsection{Fundamentação teórica}

Para fundamentar o presente relato, realizou-se a revisão bibliográfica nas bibliotecas virtuais - BVS, Scielo, Periódicos CAPES, Lilacs, Google acadêmico e Pubmed - utilizando os descritores: metodologias ativas; ensino remoto; ensino-aprendizagem; tecnologias de ensino; programa tutorial; COVID-19. Além disso, optou-se pelos trabalhos mais recentes que versassem sobre ensino-aprendizagem, metodologias ativas e tecnologias no ensino remoto. Dessa forma, propôs-se estabelecer a experiência dos estudantes com o ERE diante do cenário pandêmico, 
fazendo-os adotarem mecanismos de adaptação frente às particularidades do novo método de ensino utilizado em decorrência da pandemia do coronavírus.

\section{UTILIZAÇÃO DAS TECNOLOGIAS DIGITAIS E DAS METODOLOGIAS ATIVAS NO ENSINO REMOTO EMERGENCIAL (ERE)}

Nesse cenário, os docentes passaram por um grande desafio para aprender sobre as novas formas de ensino digitais, e, para tal, a instituição proporcionou cursos de formação para utilização das novas ferramentas tecnológicas e das metodologias ativas de aprendizagem. Diante do exposto, destaca-se a vivência dos educadores ao empregar as metodologias ativas associadas ao uso de recursos tecnológicos - e a disposição em aprender esses métodos atrelados ao novo formato de ensino. Constituiu um consenso entre os discentes que o professor atuou de maneira mediadora e incentivadora na construção do conhecimento do aluno. Nesse contexto, foi importante, no processo, a atuação docente, que adotou mecanismos para adquirir habilidades na competência digital, sustentadas por conhecimento básico no uso de computadores, com intuito de comunicação e participação em redes colaborativas via internet (LÁZARO et al., 2018).

As aulas on-line tiveram início somente no dia 17 de agosto, dada a necessidade de todo o preparo técnico-pedagógico dos docentes e discentes para as adequações à nova ferramenta de ensino. Os encontros aconteceram de forma síncrona, por meio da plataforma Google Meet, onde foi possível estabelecer a interação de todos, fosse para esclarecer dúvidas ou aprender novos conteúdos. Os momentos assíncronos foram destinados ao planejamento para a execução das atividades, individuais ou em grupos, disponibilizadas. Foi relevante a combinação de técnicas, estratégias, recursos e aplicativos, pois os alunos sentiram-se envolvidos no processo de aprendizagem. Similar a isso, o estudo feito por Souza et al. (2020) concluiu que a ferramenta metodológica Google Meet foi a mais utilizada no ensino remoto pelos discentes.

A utilização da técnica de sala de aula invertida - Flipped Classroom - despertou o interesse dos discentes para uma aprendizagem colaborativa e significativa, disponibilizando o material de aula com antecedência ao encontro síncrono para leitura prévia. Algumas ferramentas foram empregadas nesse processo como, por exemplo, a Jamboard, que tornou a aula síncrona mais dinâmica e interativa, fazendo com que os estudantes participassem de jogos educativos em tempo real; e a Google Forms com o objetivo de criar formulários on-line para que o estudante solucionasse questões de múltipla escolha e discursivas, além de outras opções. Corrobora com essa realidade o ensaio realizado sobre formas de aprendizado o qual relatou que a sala de aula invertida proporcionou a resolução e discussões de problemas que estimularam a curiosidade, desenvolvendo no aluno a habilidade de pesquisador (VALENTE, 2014).

A apresentação de seminários constituiu-se também em uma estratégia pedagógica muito importante para os discentes, tendo em vista o desenvolvimento da autonomia para se organizarem em grupos - de cinco a seis, por solicitação dos docentes - e produzir vídeos com os temas propostos, distribuindo o conteúdo a ser estudado. Semelhante a isso, um estudo sobre metodologias ativas de ensino nos cursos de licenciatura mostrou que o trabalho em grupo constituiu uma importante estratégia que ganhou destaque, pois estimulou o coletivismo e a colaboração de todos os envolvidos (DIESEL et al., 2018).

Dessa forma, evidenciam-se os aspectos positivos da participação ativa dos alunos no processo de ensino-aprendizagem a partir da formação de grupos de trabalho. Tal método foi norteador no ensino remoto, pois permitiu a estudantes - tanto dos cursos de bacharelado 
quanto dos de licenciatura - que se envolvessem de modo mais aprofundado em busca de conhecimentos.

\section{ORGANIZAÇÃO CURRICULAR ENQUANTO ASPECTO PRIMORDIAL NA FORMAÇÃO DO ENFERMEIRO}

De acordo com a proposta do PPC do curso em questão, está a de estabelecer, enquanto opção político-pedagógica, o diálogo entre o conhecimento científico, o conhecimento popular e o conhecimento construído na experiência - de forma contínua e dialética - a partir da problematização da realidade. Conforme essa perspectiva, o formando vai construindo e incorporando ao seu itinerário formativo as tecnologias de cuidado, sendo capaz de intervir no processo saúde-doença, segundo as necessidades locais e regionais de saúde (IFPE, 2015).

O curso possui dez módulos - cada um corresponde a um semestre - e carga horária total de 4.028 horas com articulação entre teoria e prática mediante a adoção de práticas educativas que proporcionem aos estudantes a oportunidade de construção das competências e habilidades cognitivas, psicomotoras e afetivas as quais o habilitarão a um exercício profissional crítico e transformador. Os programas tutoriais estão presentes do módulo I ao módulo VII, com a finalidade de apoiá-los e facilitar a adaptação dos educandos em cada módulo. Nestes, cada docente assume um grupo de até dez discentes, integrando-os e criando possibilidades para uma prática colaborativa e interdisciplinar.

A modalidade de estudos tutoriais, ou programa tutorial, compreende a formação de grupos tutoriais de aprendizagem, propiciando aos alunos participantes, sob a orientação de um professor-tutor, a realização de atividades curriculares que complementem a formação acadêmica. É comum que os estudantes vivenciem dificuldades adaptativas no ingresso do Ensino Superior, e esses componentes propõem facilitar a adaptação dos discentes em cada módulo. Nos grupos tutoriais - componentes curriculares obrigatórios -, são discutidos temas transversais necessários à formação do enfermeiro. 0 estudo em questão foi realizado, segundo os relatos e as perspectivas dos discentes da Programa Tutorial II.

A organização curricular contempla, de forma interdisciplinar, os conteúdos das áreas das Ciências Biológicas e da Saúde, das Ciências Humanas e Sociais e das Ciências da Saúde Enfermagem, e cada conteúdo disciplinar é selecionado de acordo com o eixo temático de cada módulo.

\section{SENTIMENTOS EXPERIMENTADOS PELOS ESTUDANTES DE ENFERMAGEM DURANTE O ENSINO REMOTO}

O memorial reflexivo construído pelos estudantes evidenciou que a primeira semana foi marcada por vários sentimentos negativos e preconceituosos acerca da nova forma de ensino. Os relatos dos memoriais reflexivos destacaram tal semana de aulas como a mais difícil, uma vez que, diante da nova realidade, novos obstáculos foram surgindo, como: internet de baixa qualidade, ambiente de estudos barulhento e o limitado conhecimento sobre as tecnologias digitais. Diante disso, observou-se a frustração da maior parte dos discentes.

Essa realidade também foi evidenciada no estudo sobre as necessidades dos estudantes em relação ao ensino remoto feito na FCM-UNICAMP o qual expôs os problemas enfrentados pelos 
educandos no acesso e na adequação às plataformas virtuais (APPENZELLER et al., 2020). Ao considerar as desigualdades sociais encontradas nesse contexto, era previsível o surgimento de tais problemas. Isso mostrou a necessidade da implementação de estratégias para a inclusão digital a fim de amenizar essas dificuldades. Para tal, foram priorizadas as atividades assíncronas com a disponibilização das aulas gravadas - mediante um termo de autorização da imagem por parte dos discentes. Da mesma maneira, foi elaborado um Plano de Docência On-line (PDO) com predominância das atividades assíncronas: aulas gravadas, disponibilização de materiais impressos e de uma política de auxílio financeiro para os discentes com maior vulnerabilidade social.

Além disso, as narrativas do memorial revelaram que o apoio dos docentes foi de grande relevância no processo de adaptação. Desse modo, a disciplina Programa Tutorial II mostrou-se de suma importância, visto que auxiliou na construção de métodos para encarar a nova realidade - a partir de um planejamento de estudo criado pelos discentes para as três semanas da disciplina - e fortaleceu o diálogo e o trabalho em equipe. Similar ao exposto, um estudo feito por Torina, Almeida e De Paula (2016) relatou que o tutorial foi composto por um grupo de alunos direcionados por um docente que possuía a função de tutor e que os auxiliava de maneira mais direta, o que possibilitou construir uma relação mais sólida entre professor-aluno. Nesse cenário, - tutorial valoriza a realização de atividades extracurriculares que apontam para práticas fundamentais no processo acadêmico, como: a interdisciplinaridade, o trabalho em equipe e a criatividade.

Ao longo da segunda semana, notou-se que a comunicação e o apoio dos professores, no tocante à utilização de metodologias ativas de ensino-aprendizagem, foi essencial para superar os obstáculos das aulas remotas. Tornou-se perceptível que os estudantes já estavam mais adaptados e com mais habilidades de autonomia. As metodologias ativas estimularam uma postura independente dos discentes e estes puderam contribuir com participações mais produtivas, expressando seus pontos de vista, e assumindo o protagonismo no processo de autoaprendizagem. Dessa maneira, foi possível constatar que o uso dessas metodologias predominou no ERE e isso pode justificar as características de autonomia observadas nesses estudantes (RODRIGUES; LEMOS, 2019).

Observou-se, ainda, que a partir da segunda semana os acadêmicos mostraram-se mais tranquilos em relação aos desafios impostos pelo ERE, porém muitos estavam no processo adaptativo e a maior dificuldade encontrada foi a de passar várias horas em frente ao computador. O estudo coordenado por Gomes et al. (2020), que envolveu o cenário caótico da educação brasileira em meio à pandemia, ressaltou que um dos impasses do ERE foi o cansaço e o estresse dos estudantes e educadores por passarem muito tempo expostos às telas - de tablets, notebooks ou celulares -, podendo trazer consequências desagradáveis à saúde. Contudo, há algumas formas de diminuir os riscos causados por essas ferramentas tecnológicas, como organizar os horários de estudo com intervalos de descanso, manter uma distância favorável das telas, conservar o nível de iluminação baixo e praticar exercícios físicos com frequência.

Na terceira semana, os estudantes apresentaram progresso tanto na adaptação ao novo método de ensino quanto às ferramentas digitais. Todavia, por se tratar da última semana das primeiras disciplinas, houve uma demanda maior de atividades com objetivo de concluir o módulo. Segundo os relatos, durante esse período, bastantes alunos sentiram-se sobrecarregados e com medo de não conseguirem cumprir os prazos estabelecidos dos trabalhos. Semelhante a essa realidade, um estudo sobre o Ensino Remoto Emergencial em uma graduação de enfermagem apontou que esses sentimentos são habituais, tendo em vista que no cenário pandêmico ocorreram mudanças na rotina de todos, isso pode justificar as fragilidades 
emocionais encontradas durante o presente relato (BASTOS et al., 2020). No entanto, apesar das dificuldades encontradas, houve pontos positivos, como as aulas gravadas, que deram maior mobilidade aos estudantes na gestão do seu tempo, e foram úteis para que, em caso de imprevistos, pudessem ter acesso ao conteúdo sem se prejudicarem. Com isso, essa estratégia da instituição auxiliou na maturidade dos acadêmicos em relação às aulas on-line, pois o ERE exigiu grande dedicação de educadores e discentes, colaborando com o processo de aprendizagem efetiva.

Sendo assim, no decorrer do primeiro módulo, verificou-se relativa adaptação dos discentes ao modelo de ensino-aprendizagem nas plataformas on-line, apesar dos sentimentos de medo no início das atividades remotas. Concluiu-se, ainda, que foram marcantes a persistência, a superação e muita resiliência desses alunos em meio aos desafios que o contexto propôs.

\section{CONCLUSÃO}

Diante do exposto, o ERE se fez necessário mediante as circunstâncias e foi um grande desafio a ser enfrentado, pois muitos estudantes estavam habituados ao ensino presencial e tradicional. No cenário pandêmico, dada a necessidade de utilização de tecnologias digitais, os discentes conseguiram se sobressair e adquiriram habilidades e métodos de autoaprendizagem essenciais para o processo de construção do conhecimento.

De acordo com os relatos, averiguou-se que, apesar das dificuldades que surgiram, os estudantes foram persistentes e levaram as atividades do semestre até o seu término, evitando a evasão. Algumas questões foram levantadas, visto que podem ter impactos negativos na evolução emocional e intelectual dos discentes, tais como a sobreposição de atividades das diversas disciplinas e o prazo exíguo que foi dado por alguns dos docentes. Destacaram-se nessa realidade as adversidades provindas de um contexto caótico pandêmico e que expuseram a situação socioeconômica de muitos alunos, evidenciadas pela falta de acesso à tecnologia, impossibilidade de participar dos momentos síncronos.

Além disso, ressalta-se a dificuldade em gerir o próprio tempo, dada a responsabilidade de muitos estudantes em afazeres domésticos e na demanda de trabalho para integrar a renda familiar durante o isolamento social. Apesar dos obstáculos encontrados durante as aulas, constatou-se que as estratégias adotadas pela Instituição foram essenciais para garantir aos estudantes o acesso ao material de estudo.

Há de se considerar as limitações do presente ensaio, uma vez que existem algumas lacunas inerentes ao curto tempo de produção e análise de experiências. Com isso, sugere-se que produções futuras se aprofundem nas diferentes perspectivas proporcionadas pelo ERE; entretanto, o presente estudo se fez necessário e, mesmo com os impasses, observa-se a sua relevância no âmbito educacional, pois é possível que venha a contribuir na adaptação de discentes do ensino remoto e, assim, minimizar os possíveis efeitos negativos.

\section{REFERÊNCIAS}

APPENZELLER, S. et al. Novos Tempos, Novos Desafios: Estratégias para Equidade de Acesso ao Ensino Remoto Emergencial. Revista Brasileira de Educação Médica, Brasília, v. 44, supl. 1, e155, 2020. 
Disponível em: http://www.scielo.br/scielo.php?script=sci_arttext\&pid=S0100-

55022020000500201\&lng=en\&nrm=iso. Acesso em: 8 out. 2020.

ARRUDA, E. P. Educação remota emergencial: elementos para políticas públicas na educação brasileira em tempos de Covid-19. Em Rede-Revista de Educação a Distância, Porto Alegre, v. 7, n. 1, p. 257-275, 2020. Disponivel em: https://www.aunirede.org.br/revista/index.php/emrede/article/view/621. Acesso em: 08 set. 2020.

BASTOS, M. C. et al. Ensino remoto emergencial na graduação em enfermagem: relato de experiência na covid-19. REME - Revista Mineira de Enfermagem, Belo Horizonte, v. 24, e-1335, set. 2020. Disponível em: https://cdn.publisher.gn1.link/reme.org.br/pdf/e_1335.pdf. Acesso em: 25 de set. 2020.

BRASIL. Ministério da Educação. Portaria $n^{\circ} 343$, de 17 de março de 2020. Dispõe sobre a substituição das aulas presenciais por aulas em meios digitais enquanto durar a situação de pandemia do Novo Coronavírus - COVID-19. Diário Oficial da União: seção 1, Brasília, DF, n. 53, p. 39, mar. 2020. Disponível em: http://www.planalto.gov.br/CCIVIL_03/Portaria/PRT/Portaria\%20n\%C2\%BA\%20343-20-mec.htm. Acesso em: 8 out. 2020.

BRASIL. Ministério da Saúde. Resolução Nº 510 de 07 de abril de 2016. Dispõe sobre as normas aplicáveis a pesquisas em Ciências Humanas e Sociais. Diário Oficial da União: seção 1, ed. 98, seção 1, p. 44.

Brasília, DF, 07 abr. 2016. Disponível em: https://www.in.gov.b r/materia/-

/asset_publisher/Kujrw0TZC2Mb/content/id/22917581. Acesso em: 8 out. 2020.

DIESEL, A. et al. As metodologias ativas de ensino nos cursos de licenciatura. Revista Signos, Lajeado, v. 39, n. 2, p. 72-90, 2018. Disponível em:

https://www.researchgate.net/publication/329850422_AS_METODOLOGIAS_ATIVAS_DE_ENSINO_NOS_C URSOS_DE_LICENCIATURA. Acesso em: 16 out. 2020.

DUTRA E SILVA, A. et al. Interdisciplinaridade e ensino remoto. Seminário de atualização de práticas docentes, Anápolis, v. 2, n. 2, out. 2020. Disponível em:

http://anais.unievangelica.edu.br/index.php/praticasdocentes/article/view/5715. Acesso em: 9 out. 2020.

GOEDERT, L.; ARNDT, K. B. F. Mediação Pedagógica e Educação Mediada por Tecnologias Digitais em Tempos de Pandemia. Criar Educação, Criciúma, v. 9, n. 2, 2020. Disponível:

http://periodicos.unesc.net/criaredu/article/view/6051. Acesso em: 07 jan. 2021

GOMES, V. T. S. et al. A Pandemia da Covid-19: Repercussões do Ensino Remoto na Formação Médica.

Revista Brasileira de Educação Médica, Brasília, v. 44, n. 4, e114, 2020. Disponível em:

http://www.scielo.br/scielo.php?script=sci_arttext\&pid=S0100-55022020000400602\&lng=en\&nrm=iso.

Acesso em: 15 out. 2020.

HODGES, C. et al. As diferenças entre o aprendizado online e o ensino remoto de emergência. Revista da Escola, Professor, Educação e Tecnologia, Recife, v. 2, 2020. Disponível em:

http://escribo.com/revista/index.php/escola/article/view/17. Acesso em: 9 out. 2020.

INSTITUTO FEDERAL DE PERNAMBUCO (IFPE). Projeto Pedagógico do curso de graduação em enfermagem. Pesqueira: IFPE, 2015. Disponível em:

https://www.ifpe.edu.br/campus/pesqueira/cursos/superiores/bacharelados/enfermagem/proj eto-pedagogico/projeto pedagogico enfermagem.pdf. Acesso em: 14 fev. 2021.

JOYE, C. R.; MOREIRA, M. M.; ROCHA, S. S. D. Distance Education or Emergency Remote Educational Activity: in search of the missing link of school education in times of COVID-19. Research, Society and 
Development, [S. I.], v. 9, n. 7, p. e521974299, 2020. Disponível em:

https://rsdjournal.org/index.php/rsd/article/view/4299. Acesso em: 5 jan. 2021.

LÁZARO, A. C.; SATO, M. A. V.; TEZANI, T. C. R. Metodologias ativas no ensino superior: o papel do docente no ensino presencial. In: CIET: ENPED: 2018 - EDUCAÇÃO E TECNOLOGIAS: DOCÊNCIA E MEDIAÇÃO PEDAGÓGICA, 2018, São Carlos. Anais [...]. São Carlos: CIET:EnPED, 2018. Disponível em: https://cietenped.ufscar.br/submissao/index.php/2018/article/view/234. Acesso em: 16 out. 2020.

MACHADO, K. G. W. As metodologias ativas na educação superior. In: Seminário Internacional Pessoa Adulta, Saúde e Educação, 4., 2018, Porto Alegre. Anais [...]. Porto Alegre: SIPASE, 2018. Disponível em: https://editora.pucrs.br/edipucrs/acessolivre//anais/sipase/assets/edicoes/2018/arquivos/30.pdf. Acesso em: 03 set. 2020.

MOREIRA, J. A. M.; HENRIQUES, S.; BARROS, D. Transitando de um ensino remoto emergencial para uma educação digital em rede, em tempos de pandemia. Dialogia, São Paulo, n. 34, p. 351-364, jan./abr. 2020. Disponível em: https://repositorioaberto.uab.pt/handle/10400.2/9756. Acesso em: 8 out. 2020.

RODRIGUES, K. G.; LEMOS, G. A.; Metodologias ativas em educação digital: possibilidades didáticas inovadoras na modalidade EAD. Ensaios Pedagógicos, Sorocaba, v. 3, n. 3, p. 29-36, set. 2019. Disponível em: http://www.ensaiospedagogicos.ufscar.br/index.php/ENP/article/view/156. Acesso em: 22 out. 2020.

SOUZA, J. L. et al. Metodologias remotas de ensino em tempos de Covid-19: estudo no curso de Ciências Contábeis da Universidade Federal do Ceará (UFC). In: USP International Conference in Accounting, 20., 2020, São Paulo. Anais [...]. São Paulo: FEA-USP, 2020. Disponível em: https://congressousp.fipecafi.org/anais/20UspInternational/ArtigosDownload/2890.pdf. Acesso: 27 set. 2020.

TORINA, H. F.; ALMEIDA, L. O.; DE PAULA, J. S. História do Programa de Educação Tutorial da FMRP-USP. Medicina, Ribeirão Preto, v. 49, n. 4, p. 374-380, 2016. Disponível em: https://core.ac.uk/download/pdf/268327969.pdf. Acesso em: 15 out. 2020.

VALENTE, J. A. Blended learning e as mudanças no ensino superior: a proposta da sala de aula invertida. Educar em revista, Curitiba, n. 4, p. 79-97, 2014. Disponível em: https://www.redalyc.org/pdf/1550/155037796006.pdf. Acesso em: 16 out. 2020.

WANDSCHEER, K. T. Ensino Remoto: um caminhar de possibilidades educativas. In: PALÚ, J.; SCHÜTZ, J. A.; MAYER, L. (Org.). Desafios da educação em tempos de pandemia. Cruz Alta: Ilustração, 2020. Disponível em: https://www.sed.sc.gov.br/documentos/ensino-89/8839-livro-desafios-da-educacao-emtempos-de-pandemia. Acesso em: 05 jan. 2021. 


\section{APÊNDICE}

\section{REGISTRO DO MEMORIAL DA TRAJETÓRIA DISCENTE NO PROGRAMA TUTORIAL II}

Nome do(a) Discente:

\begin{tabular}{|ll|l|}
\hline $\begin{array}{l}\text { Município/Estado } \\
\text { procedência: }\end{array}$ & de & \\
\hline $\begin{array}{l}\text { Município/Estado } \\
\text { residência: }\end{array}$ & de & \\
\hline
\end{tabular}

\begin{tabular}{|c|}
\hline Atividades que desenvolve no campus além do ensino \\
\hline \begin{tabular}{|l} 
Pesquisa: ( ) Não ( ) Sim. Se sim, especificar área temática: \\
\end{tabular} \\
\hline Extensão: ( ) Não ( ) Sim. Se sim, especificar área temática: \\
\hline Monitoria: ( ) Não ( ) Sim. Se sim, especificar área temática: \\
\hline
\end{tabular}

Ao longo da sua trajetória estudantil, qual (is) tipo (s) de abordagem pedagógica (s) mais predominou e que mais foi (foram) vivenciada (s) por você? (Pode marcar mais de uma alternativa)

\begin{tabular}{||||l|l||}
\hline $\begin{array}{l}\text { ( ) Docência tradicional (o professor } \\
\text { transmitindo as aulas) }\end{array}$ & ( ) Educação a Distância (EaD) \\
\hline $\begin{array}{l}\text { ( ) Metodologias ativas (com dinâmicas, rodas } \\
\text { de conversa, tutoria, seminários e outras. }\end{array}$ & ( ) Ensino híbrido \\
\hline
\end{tabular}

Registro de expectativas em relação ao programa tutorial II (Registre de forma suscinta as suas expectativas, sobretudo diante do atual cenário pandêmico em que se faz necessário o ensino remoto)

Seu memorial de trajetória no Programa Tutorial II (Aqui você descreve como tem sido sua adaptação às atividades remotas, destacando as reflexões mais relevantes nesse processo, tais como: vivências, aprendizagens, dificuldades, etc.)

Semana 1 (17 a 21/08/2020): Comentários/Observações mais relevantes

Semana 2 (24 a 28/08/2020): Comentários/Observações mais relevantes

Semana 3 (31 a 05/08/2020): Comentários/Observações mais relevantes

Fonte: Adaptado pelo docente do programa tutorial II, através do instrumento de avaliação do Instituto de Ensino e Pesquisa (IEP)/Hospital Sírio Libanês (2021). 